\title{
Knockdown of c-Met inhibits cell proliferation and invasion and increases chemosensitivity to doxorubicin in human multiple myeloma $\mathrm{U} 266$ cells in vitro
}

\author{
WENZHONG QUE and JUNMIN CHEN \\ Department of Hematology and Rheumatology, The First Affiliated Hospital of Fujian Medical University, Fujian, P.R. China
}

Received October 6, 2010; Accepted January 6, 2011

DOI: $10.3892 / \mathrm{mmr} .2011 .426$

\begin{abstract}
Met, a receptor tyrosine kinase and its ligand, hepatocyte growth factor, are critical in cellular proliferation, motility and invasion and confer resistance to specific chemotherapeutic drugs. However, little is known about the impact of c-Met knockdown on the biological functions of human multiple myeloma U266 cells. The present study was designed to determine the role of c-Met in the proliferation and invasion of U266 cells, using RNA interference technology in vitro. In our study, the c-Met short hairpin RNA (shRNA) was successfully transfected into U266 cells, which resulted in the significant inhibition of transcription and expression of c-Met. The down-regulation of c-Met inhibited the proliferation potential, adherence and invasiveness of U266 cells, and also increased chemosensitivity to doxorubicin. The c-Met shRNA in U266 cells induced apoptosis and increased the accumulation of cleavage PARP and cleavage caspase-3. However, the expression of Bcl-2 and Bax did not change following the c-Met knockdown. Taken together, our data reveal that the down-regulation of c-Met inhibits proliferation and invasion and increases the chemosensitivity of U266 cells. Thus, the targeting of c-Met could be an effective therapeutic approach against multiple myeloma.
\end{abstract}

\section{Introduction}

Multiple myeloma (MM) is the second most common hematological malignancy, characterized by the clonal proliferation of neoplastic plasma cells in the bone marrow (BM). At present, $\mathrm{MM}$ is an incurable disease, in spite of the fact that most patients to a certain extent respond to chemotherapy. High-dose chemotherapy with stem cell support has achieved

Correspondence to: Dr Junmin Chen, Department of Hematology and Rheumatology, The First Affiliated Hospital of Fujian Medical University, Chating, Fuzhou, P.R. China

E-mail: drjunminchen@hotmail.com

Key words: U266 cells, c-Met, short hairpin RNA, proliferation, invasion higher response rates than conventional therapies, but few patients remain in long-term remission. New effective anticancer targets for both early and advanced MM is a dynamic research area (1-5).

The interaction of MM cells with extracellular matrix (ECM) proteins and BM cells, as well as factors in the BM milieu (cytokines, chemokines and angiogenesis), play a crucial role in MM pathogenesis (6-9). The interaction of MM cells with the BM microenvironment activates MM cell proliferation and the anti-apoptotic signaling cascades $(10,11)$. These molecular events are triggered directly, via cell adhesion molecule-mediated interactions, or indirectly by growth factors released by BM stromal cells (BMSCs), MM cells or both $(12,13)$.

Hepatocyte growth factor (HGF) is a multifunctional protein. c-Met is the receptor for HGF, a protein product of a proto-oncogene (14). It is a transmembrane tyrosine kinase with structural and functional features of a growth factor receptor (15). On binding with its ligand, autophosphorylation of the receptor stimulates its intrinsic tyrosine kinase activity with resultant changes in cellular motility, growth and invasion. c-Met overexpression has been found in numerous human tumors $(16,17)$. Previous studies have revealed that c-Met and its ligand HGF are overexpressed in human myeloma cell lines (JJN-3, U-266, OH-2 and JW) and primary human MM cells (18). In addition, HGF has been reported to promote MM cell growth and migratrion in vitro (19). In the present study, we investigated the role of c-Met in the proliferation and invasion of human MM U266 cells using RNA interference (RNAi) technology in vitro.

RNAi is a sequence-specific, post-transcriptional gene silencing method initiated by double-stranded RNAs, which are homologous to the target gene (20). In the present study, the highly expressed c-Met U266 cell line was used as a cellular model of MM for gene studying.

\section{Materials and methods}

Cell culture. ECV304 and U266 cells (Wuhan University, P.R. China) were suspended in RPMI-1640 medium (Gibco BRL, Grand Island, NY, USA) supplemented with $10 \%$ fetal calf serum (Gibco) and cultured at $37^{\circ} \mathrm{C}$ in a humidified atmosphere containing $5 \% \mathrm{CO}_{2}$. 
Table I. The sequences of the designed c-Met-specific shRNAs.

\begin{tabular}{ll}
\hline shRNA & Sequence \\
\hline shRNA-Met & 5'-GATCCGCAAGCCAGATTCTGC \\
& CGAACCATCAAGAGTGGTTCG \\
& GCAGAATCTGGCTTGCTTT TTA-3' \\
& 5'-AGCTTAAAAAGCAAGCCAGAT \\
& TCTGCCGAACCACTCTTGATG \\
& GTTCGGCAGAATCTGGCTTGCG-3' \\
shRNA-control & 5'-GATCCGTCAGCACTCTCGAAT \\
& CAGATGCTCAAGAGGCATCTG \\
& ATTCGAGAGTGCTGACTTTTTA-3' \\
& 5'-AGCTTAAAAAGTCAGCACTCT \\
& CGAATCAGATCGCTCTTGAGCATC \\
& TGATTCGAGAGTGCTGACG-3' \\
\hline
\end{tabular}

Construction of short hairpin RNA (shRNA) expression vectors. The vector pSilencer $3.1 \mathrm{H} 1$ neo (Ambion Inc., Austin, TX, USA) was used to generate shRNA specific for c-Met. The region of c-Met mRNA (GenBank: NM_000245) ranging from 1,045 to 1,067 bp was selected as the RNAi target site, designated as shRNA-Met (21). The template oligonucleotides encoding the target sequence were designed and synthesized. shRNA-control encoding a non-specific shRNA was also synthesized and used as the negative control (Table I). These oligonucleotides were annealed and subcloned into the HindIII and BamHI sites of the vector according to the manufacturer's instructions. These recombinant vectors were designated as pSilencer-shRNA-Met and pSilencer-shRNA-control, respectively.

Transfection of cells. Transfection of U266 cells was performed using the Amaxa cell optimization kit V (Amaxa, Köln, Germany) according to manufacturer's instructions, using pSilencer-shRNA-Met and pSilencer-shRNA-control as mentioned above. These cells were cultured in the presence of $400 \mu \mathrm{g} / \mathrm{ml} \mathrm{G} 418$ (Gibco) for 4 weeks. The positive clones were picked and expanded to establish cell lines. RT-PCR and Western blot analysis were used to identify the successful transfection. The stable transfection cell clones were designated as U266/shRNA-Met and U266/shRNA-control, respectively.

RT-PCR analysis. Total RNA was isolated from cells, using TRIzol reagent (Invitrogen). RNA (4 $\mu \mathrm{g})$ was reverse transcribed to cDNA by the Thermoscript RT-PCR System reagent (Gibco). Primers were designed for the PCR reaction. The sequences for human c-Met were 5'-CCGAGGTGTATGTATGAGTG-3' (sense) and 3'-GGAAGAGATTGTAGAGAGGA-5' (antisense). Primers for the control GAPDH were 5'-GAGGTTCACTGCATATTCTCC-3' (sense) and 5'-GTCTGAGCATCTAGAGTTTCC-3' (antisense). The PCR amplification consisted of 35 cycles: $15 \mathrm{sec}$ at $94^{\circ} \mathrm{C}$ for denaturing, $30 \mathrm{sec}$ at $58^{\circ} \mathrm{C}$ for annealing and $45 \mathrm{sec}$ at $72^{\circ} \mathrm{C}$ for elongation. Bands obtained on $1.5 \%$ agarose gel electrophoresis were analyzed and quantified with an image analyzer. The transcript levels were normalized according to the GAPDH transcripts. Results were expressed in relation to the control value.

Western blot analysis. The cultured cells $\left(1 \times 10^{6}\right)$ were collected and lysed. Protein concentration was determined by the Lowry method using BSA as the standard. Equal amounts of protein were separated on 6-15\% SDS/PAGE gels. The protein was then electrophoretically blotted onto polyvinylidene fluoride (PVDF) membranes, which were blocked with TBST containing 5\% non-fat milk at $4^{\circ} \mathrm{C}$ overnight and then incubated with anti-cleaved caspase-3 (Asp175) and anticleaved PARP (Asp214; Cell Signaling Technology, Beverly, MA, USA), anti-c-Met, anti-bax, anti-bcl-2 and GAPDH (Santa Cruz, USA) for $2 \mathrm{~h}$. After washing with TBST, the blots were incubated with HRP-labeled secondary antibodies for $2 \mathrm{~h}$ at room temperature. The blots were visualized by the enhanced chemiluminescence (ECL) reagent kit (Beyotime, P.R. China).

Cell proliferation assay. Before the cell proliferation assay, trypan blue exclusion test of cell viability was performed and the viability of the three groups of cells (untreated U266, U266/shRNA-control and U266/shRNA-Met) was $>98 \%$. Cell proliferation in vitro was analyzed with 3-(4,5-dimethylthiazol-2-yl)-2, 5-diphenyltetrazolium bromide (MTT; Sigma, USA). Briefly, cells were seeded in quadruplicate at a density of $2 \times 10^{3}$ cells/well in 96-well plates in $200 \mu \mathrm{l}$ of medium and cultured for 24,48 and $72 \mathrm{~h}$, respectively. Medium without any cells $(200 \mu \mathrm{l})$ was provided as the blank control. Subsequently, $20 \mu \mathrm{l}$ of MTT substrate $(5 \mathrm{mg} / \mu \mathrm{l}$ in PBS) were added to each well and the plates were returned to standard cell incubator conditions for $4 \mathrm{~h}$. After a brief centrifugation, supernatants were carefully removed and $200 \mu \mathrm{l}$ DMSO were added to each well. After the insoluble crystals were completely dissolved, colorimetric analysis was performed (wavelength, $490 \mathrm{~nm}$ ). The inhibition rate was calculated as follows: 100\%-(OD value of U266 cells/OD value of blank control)\%. Each experiment was carried out in triplicate.

Flow cytometry analysis of apoptosis. Cells were washed twice with ice-cold PBS and fixed with $70 \%$ ethanol at $4^{\circ} \mathrm{C}$ overnight. After washing with $\mathrm{PBS}$, cells were incubated in $0.5 \mathrm{ml}$ PBS containing $50 \mu \mathrm{g} / \mathrm{ml}$ RNase A for $30 \mathrm{~min}$ at $37^{\circ} \mathrm{C}$ and then PI was added to achieve the final concentration of $50 \mu \mathrm{g} / \mathrm{ml}$ for $30 \mathrm{~min}$ on ice in the dark. The resultant cell suspension was then subjected to flow cytometry analysis (Coulter Epics XL). The percentage of apoptotic cells (sub- $\mathrm{G}_{1}$ ) and cells in the $G_{0} / G_{1}, S$ and $G_{2} / M$ phases was calculated.

Adhesion assay. Cells were seeded in quadruplicate at a density of $1 \times 10^{4}$ cells/well in 96-well plates coated with $10 \mathrm{~g} / 1$ BSA, $50 \mathrm{mg} / 1$ Matrigel or $10 \mathrm{mg} / \mathrm{l}$ fibronectin (Fn). After the cells were cultured at $37^{\circ} \mathrm{C}$ for $60 \mathrm{~min}$, MTT assay was performed as described above (22-25). BSA-coated wells were provided as the negative control. The percentage of adhesion was calculated as follows: $100 \%-(O D$ value of treated/OD 
A
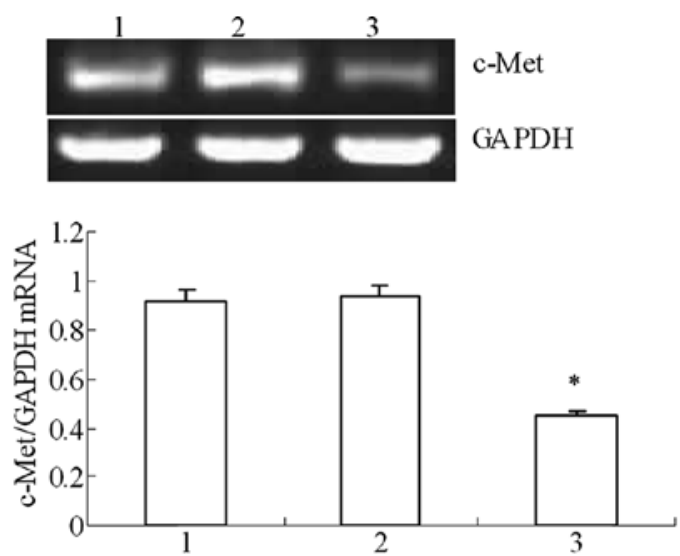

B
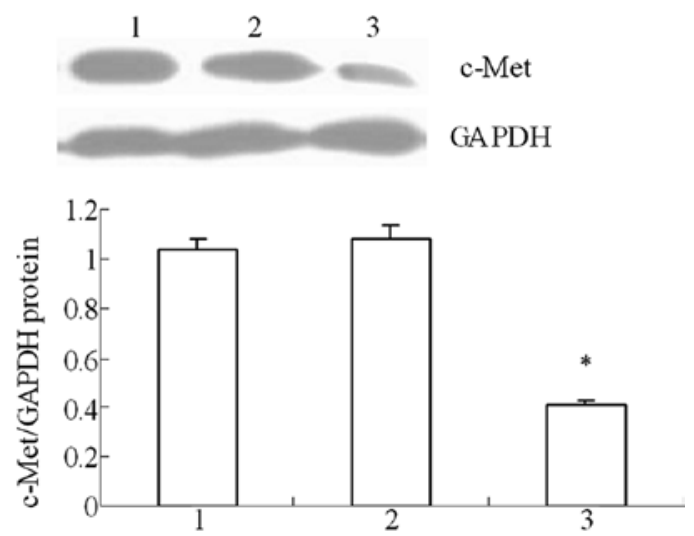

Figure 1. Effect of c-Met/shRNA on the c-Met mRNA expression and the c-Met protein level of U266 cells. (A) Relative mRNA levels were analyzed by RT-PCR. Lanes 1-3 represent the lysates of untreated U266, U266/shRNAcontrol and U266/shRNA-Met cells, respectively. The density of bands on the membrane was scanned and analyzed with an image analyzer. The transcript levels were normalized according to GAPDH transcripts. (B) The c-Met protein expression by Western blotting. Lanes 1-3 represent the lysates of untreated U266, U266/shRNA-control and U266/shRNA-Met cells, respectively. The cell lysates were separated on $6 \%$ SDS-PAGE gel, transferred to PVDF membrane and probed with anti-c-Met. Protein contents were normalized by probing the same membrane with anti-GAPDH. The density of bands on the membrane was scanned and analyzed with an image analyzer. Results are expressed in relation to the control value. $\mathrm{P}<0.01$ compared with untreated U266 or U266/shRNA-control cells.

value of negative control)\%. Each experiment was carried out in triplicate.

U266 cell adherence to ECV304 cells. ECV304 cells were plated onto 96 -well plates at a density of $5 \times 10^{4}$ cells/well. After 48-h incubation, the supernatant was aspirated and cells were resuspended at a density of $5 \times 10^{4}$ cells/well. After $30 \mathrm{~min}$, the wells were gently washed twice with PBS to remove unattached cells. Rose bengal $(25 \% ; 100 \mu \mathrm{l})$ was added to each well and left standing for $5 \mathrm{~min}$. The supernatant was then aspirated, the wells were gently washed twice with PBS and finally $200 \mu 1$ of $95 \%$ ethanol/PBS (1:1) were added to each well. After 20-min incubation, the absorbance was recorded at $570 \mathrm{~nm}$.

Invasion assay. The invasion assay was performed, using Transwell polycarbonate membrane (Corning, Lowell, MA, USA) following the manufacturer's instructions. Briefly, the underside of each polycarbonate microporous membrane was coated with Matrigel $(1: 100)$ at $37^{\circ} \mathrm{C}$ for $5 \mathrm{~min}$ and left standing overnight. The membrane was then inserted into 24-well plates, forming upper and lower compartments, and $50 \mu \mathrm{l}$ Matrigel (1:30) and $200 \mu \mathrm{l}$ sterile water were added to the upper compartment and left standing at $37^{\circ} \mathrm{C}$. After 2 days, $200 \mu \mathrm{l}$ of the invasion buffer [2 $\mathrm{ml} \mathrm{BSA}(2 \%)+38 \mathrm{ml}$ RPMI-1640] were added into the upper compartment. After 1 $\mathrm{h}$, the upper compartment fluid was aspirated. Cells at a density of $5 \times 10^{4}$ cells/well were added into the upper compartment and $800 \mu \mathrm{l}$ of the Fn solution $(10 \mu \mathrm{g} / \mathrm{ml})$ were added into the lower compartment. The cells were allowed to migrate for $48 \mathrm{~h}$. The inserted membranes were then fixed in $10 \%$ formalin, stained with hematoxylin and eosin and rinsed by dipping in water. The cells on the upper surface of the membrane were removed with a cotton bud. The membranes were airdried overnight, excised from the insert and mounted onto glasss slides for microscopic analysis. The migrated cells were counted at high-power magnification (x40) from four randomly selected fields. Each experiment was repeated three times.

Increased chemosensitivity to doxorubicin. The cells were seeded in triplicate on 96-well plates at $1 \times 10^{4}$ cells/well and incubated for $24 \mathrm{~h}$. Then the medium was gently removed and replaced with fresh medium, containing doxorubicin (Sigma) in varying concentrations (doxorubicin ${ }^{+}$), that is, $0.1 \mathrm{X}$ peak plasma concentration (PPC), 1X PPC and 10X PPC, and with the medium without doxorubicin as the control. After 48-h incubation, the cells were treated with MTT as described above. The inhibition rate was calculated as follows: $100 \%-O D 490\left({ }_{\text {doxorubicin }+}\right) / O D 490\left(_{\text {doxorubicin- }}\right) \%$. The assay was repeated three times.

Statistical analysis. The data were expressed as the means \pm $\mathrm{SD}$, and the Student's t-test was used to determine the significance of differences in multiple comparisons. A value of $\mathrm{p}<0.05$ was considered to be statistically significant.

\section{Results}

Knockdown of c-Met efficiently suppresses c-Met expression. The silencing effects of c-Met-specific shRNA in U266 cells was first evaluated using RT-PCR and Western blot analyses. The results revealed that the c-Met mRNA expression in the U266/shRNA-Met cells was $45.4 \pm 1.9 \%$, significantly lower than that in the U266/shRNA-control cells $(91.7 \pm 3.1 \%)$ or the untreated U266 cells $(93.7 \pm 2.7 \%$; p $<0.05$; Fig. 1A). Western blot analysis revealed similar results. The density of the c-Met protein in the U266/shRNA-Met cells was $40.9 \pm 2.4 \%$, significantly lower than that in the U266/shRNA-control cells $(99.8 \pm 2.9 \%)$ or the untreated U266 cells $(99.4 \pm 3.8 \% ; \mathrm{p}<0.05$; Fig. 1B). There was no significant difference between the U266/shRNA-control and the untreated U266 cells ( $p>0.05$ ).

Knockdown of c-Met inhibits cell proliferation, induces cell cycle arrest and promotes apoptosis in U266 cells. We then investigated whether c-Met shRNA decreases the proliferation of U266 cells. As shown in Fig. 2, compared to the untreated U266 cells, the proliferation capacity of U266/shRNA-Met was inhibited by $72.51 \pm 1.49 \%(\mathrm{p}<0.01), 66.08 \pm 1.91 \%(\mathrm{p}<0.01)$ and $68.27 \pm 1.87 \%(\mathrm{p}<0.01)$ at 24,48 and $72 \mathrm{~h}$, respectively. There 


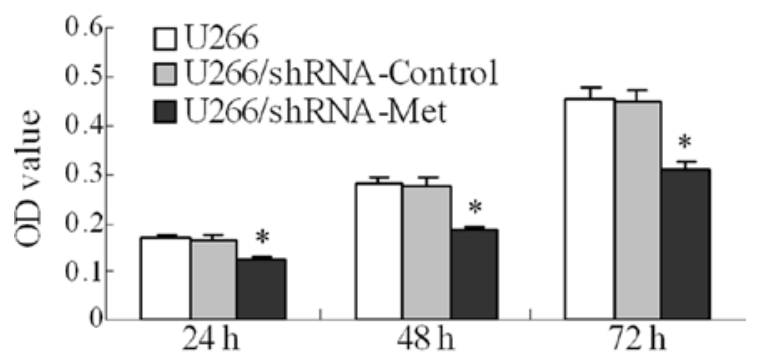

Incubation time after cells seeded (hours)

Figure 2. Effect of c-Met/shRNA on U266 cell proliferation. MM cells (untreated U266, U266/shRNA-control and U266/shRNA-Met cells) seeded in 96-well microplates, were cultured for for 24,48 and $72 \mathrm{~h}$, and their numbers were determined by absorbance. ${ }^{*} \mathrm{P}<0.01$ compared to the untreated U266 or U266/shRNA-control cells.

A

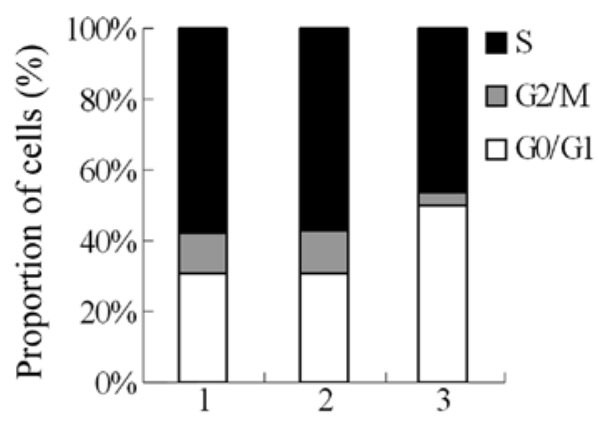

B

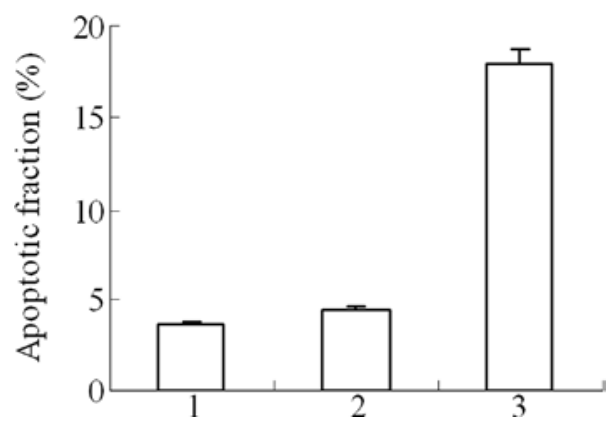

Figure 3. Effect of c-Met/shRNA on U266 cell apoptosis and cell cycle distribution. MM cells (untreated U266, U266/shRNA-control and U266/ shRNA-Met cells) seeded in 6-well plates were cultured for $48 \mathrm{~h}$. Cells were fixed with ethanol and stained with PI and then sub-G1 and cell-cycle distribution was analyzed by flow cytometry. (A) Cell-cycle distribution. (B) The porprotion of sub-G1. Lanes 1-3 represent the untreated U266, the U266/ shRNA-control and the U266/shRNA-Met cells, respectively. The data were obtained from three independent experiments.

was no significant difference in the proliferation capacity between the U266/shRNA-control and untreated U266 cells $(\mathrm{p}>0.05)$. To determine the apoptosis-inducing potential of c-Met/shRNA in U266 cells, flow cytometric analysis of PI-stained cells was performed. As indicated in Fig. 3A, the percentage of cells in the $\mathrm{G}_{0} / \mathrm{G}_{1}$ phase in the U266/shRNA-Met group (50.1\%) was much higher than that observed in the U266 shRNA-control group (30.3\%). The percentages of cells in the $\mathrm{S}$ and $\mathrm{G}_{2} / \mathrm{M}$ phase in the U266/shRNA-Met group were 3.98 and $45.9 \%$, respectively, lower than those in control group, which were 12.1 and $57.6 \%$, respectively. The apoptotic rate in U266/shRNA-Met cells was $17.9 \%$, much higher than that (4.39\%) in the control group (Fig. 3B).

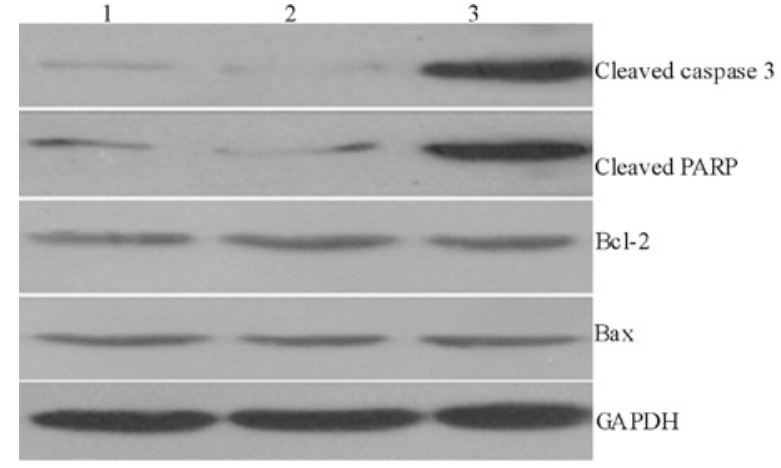

Figure 4. Effects of c-Met/shRNA on the expression of apoptotic proteins in U266 cells. The cell lysates were separated on 6-15\% SDS-PAGE gel, transferred to a PVDF membrane and probed with anti-cleaved PARP (89 kDa), anti-cleaved caspase-3 (17 kDa), anti-Bcl-2 and anti-Bax. Protein contents were normalized by probing the same membrane with anti-GAPDH. Lanes 1-3 represent the lysate of untreated U266, U266/shRNA-control and U266/shRNA-Met cells, respectively.

$\mathbf{A}$

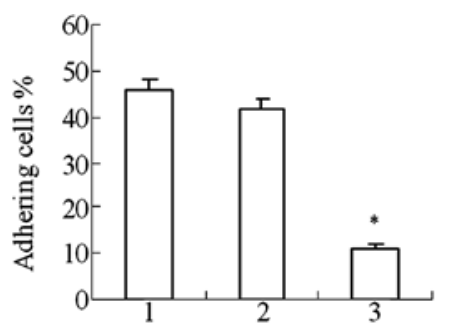

U266 cell adhesion to ECM (Fibronection)

B

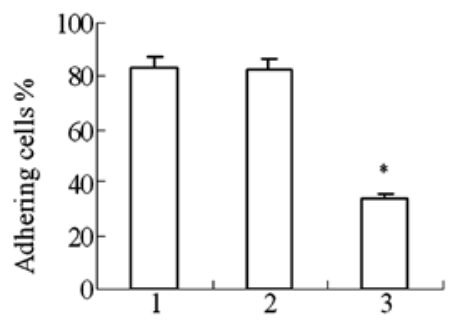

U266 cell adhesion to ECM (Matrigel)

C

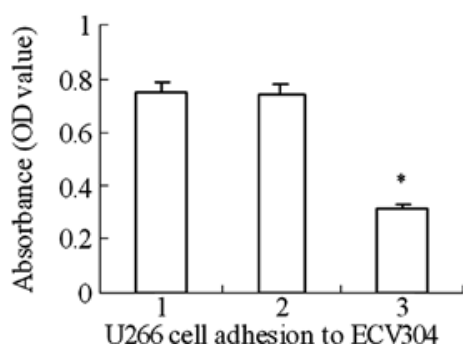

Figure 5. Effects of c-Met/shRNA on U266 cell adhesion. (A) U266 cell adhesion to ECM (Fn); (B) U266 cell adhesion to ECM (Matrigel); (C) U266 cell adhesion to ECV304 cells. Lanes 1-3 represent the untreated U266, U266/shRNA-control and U266/shRNA-Met cells, respectively. The data were obtained from three independent experiments. ${ }^{*} \mathrm{P}<0.01$ compared to the untreated U266 or U266/shRNA-control cells.

Effects of c-Met on cell apoptosis-associated protein expression. We have demonstrated that the knockdown of c-Met induces U266 cell apoptosis. To further elucidate how the c-Met regulation affects apoptosis, caspase-3, PARP, bcl-2 and bax which are associated with apoptosis, were detected 


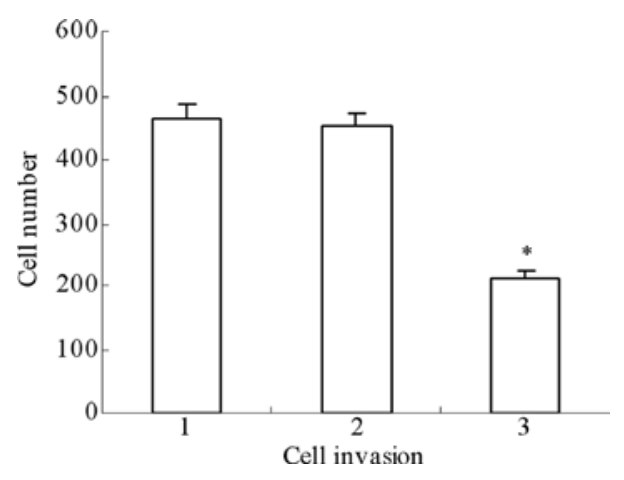

Figure 6. Effects of c-Met/shRNA on the invasion of U266 cells. The average number of cells that invaded through the filter was counted. Lanes 1-3 represent untreated U266, U266/shRNA-control and U266/shRNA-Met cells, respectively. The data were obtained from three independent experiments. ${ }^{*} \mathrm{P}<0.01$ compared to the untreated U266 or U266/shRNA-control cells.

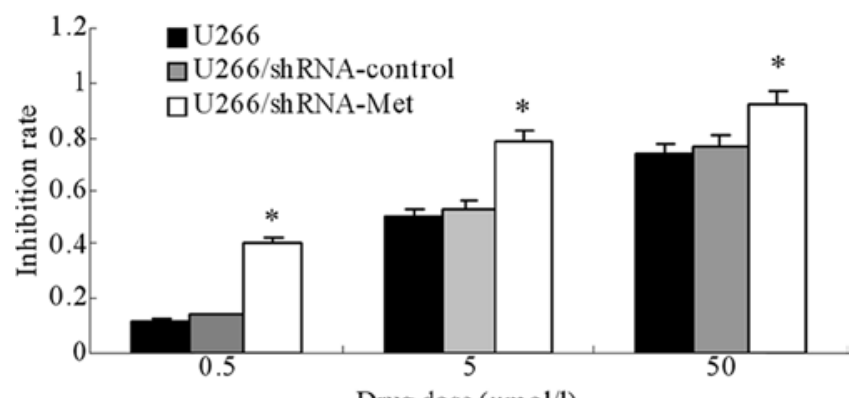

Drug dose $(\mu \mathrm{mol} / \mathrm{l})$

Figure 7. Effects of c-Met/shRNA on doxorubicin sensitivity of U266 cells. MM cells (untreated U266, U266/shRNA-control and U266/shRNA-Met cells) were treated with various concentrations of doxorubicin. Cell vialility was determined by MTT assay. ${ }^{*} \mathrm{P}<0.01$ compared to the untreated U266 or U266/shRNA-control cells.

by Western blot analysis. As depicted in Fig. 4, the expression levels of cleaved PARP and cleaved caspase-3 were increased in the U266/shRNA-Met, compared to the untreated U266 cells or the U266/shRNA-control cells. However, in our present study, no significant differences were found in the expression of both Bcl-2 and Bax proteins in the U266/ shRNA-Met cells compared to the untreated U266 cells or the U266/shRNA-control cells.

Effects of c-Met on cell adhesion. Suppressing c-Met expression had a clear inhibitory effect on the adhesion of transfected U266 cells to ECM (Fn and Matrigel) and to ECV304 cells. The percentages of adhesion to ECM (Fn) were $45.9 \pm 2.4$, $41.7 \pm 4.7$ and $11.2 \pm 1.7 \%$ for the untreated U266, the U266/ shRNA-control and U266/shRNA-Met cells (Fig. 5A). The percentages of adhesion to ECM (Matrigel) were 83.1 \pm 6.2 , $82.6 \pm 9.1$ and $34.1 \pm 2.5 \%$ for the untreated U266, U266/ shRNA-control and U266/shRNA-Met cells, respectively (Fig. 5B). In addition, the U266 cell line revealed various adherence capacities to ECV304. The absorbance values were $0.751 \pm 0.007,0.742 \pm 0.004$ and $0.312 \pm 0.005$ for the untreated U266, U266/shRNA-control and U266/shRNA-Met cells, respectively (Fig. 5C). Thus, the adhesion of shRNA-Met to ECM and to ECV304 cells was significantly suppressed $(\mathrm{P}<0.01)$.

Effects of c-Met on cell invasion. As depicted in Fig. 6, for each $\times 400$ field under the microscope, the number of migrated U266/shRNA-Met cells on the membrane was $211 \pm 14$, significantly lower than that of the U266/shRNA-control $(451 \pm 11$; $\mathrm{p}<0.01)$ or untreated U266 cells $(463 \pm 10 ; \mathrm{p}<0.01)$.

Increased chemosensitivity to doxorubicin. We investigated whether the inhibition of c-Met by shRNA affected the sensitivity of U266 cells to the anti-tumor drug, doxorubicin. At all the indicated concentrations of doxorubicin, the inhibition rate in the U266/shRNA-Met cells was markedly higher than that in the untreated U266 or U266/shRNA-control cells ( $<<0.01$ ). There was no significant difference between the U266/shRNAcontrol and the untreated U266 cells ( $>>0.05$; Fig. 7).

\section{Discussion}

HGF/c-Met has been proved to be involved in the progression of many malignancies and the spread of disease (26-29). In MM patients, elevated levels of HGF have been found in serum and BM, compared to healthy controls (30-33), indicating that a high serum level of HGF at the time of diagnosis has a strong negative prognostic impact $(30,33)$. Previous basic studies have also revealed that c-Met and its ligand HGF are overexpressed in human myeloma cell lines (JJN-3, U-266, $\mathrm{OH}-2$ and $\mathrm{JW}$ ) and primary human MM cells $(18,34,35)$.

The silencing of c-Met by shRNA has been reported in various tumor cells $(36,37)$. This suggests that shRNA is an effective technique for tumor study and treatment. However, there have been no reports of silencing c-Met in myeloma cells until recently. The nucleofector technique is a new non-viral transfection method, especially designed for hard-to-transfect cell lines (38). In the present study, we successfully transfected shRNAs targeting the c-Met gene into the human MM cell line, U266, using the nucleofector technique, and the c-Met expression was effectively inhibited at both the mRNA and protein levels.

A recent study has also indicated that c-Met signaling could be important in myeloma cell proliferation (39). We examined the effect of c-Met silencing on the proliferation capacity of U266 cells. The proliferation capacity of shRNA-Met cells was suppressed compared to the untreated U266 or U266/ shRNA-control cells. This is in agreement with results from other studies, in that the down-regulation of c-Met leads to myeloma cell death, thus indicating that the level of c-Met expression is important for the survival of myeloma cells $(40,41)$.

It has also been reported that c-Met signaling results in the inhibition of proliferation and induction of apoptosis in a wide variety of tumors. For example, exposure to ARQ 197, a novel and selective inhibitor of the human c-Met receptor tyrosine kinase, resulted in the inhibition of proliferation of c-Met-expressing cancer cell lines, as well as the induction of caspase-dependent apoptosis in cell lines (42). In vitro pharmacological c-Met inhibition and siRNA targeted against c-Met triggered caspase-dependent apoptosis in DLBCL cells (43) and HGF has strong proliferative and anti-apoptotic effects on 
both MM cell lines and primary MM cells (44). In agreement with these results, our study reveals that the decreased proliferation capacity of the U266 cells in the shRNA-Met group is associated with increased rates of apoptosis and that cell cycle arrest occurs at the $\mathrm{G}_{0} / \mathrm{G}_{1}$ phase, as measured by flow cytometric analysis of PI-stained cells.

Active caspases play an important role in the induction of apoptosis. After caspase-3 was activated, PARP was cleaved (45). The cleavage of PARP has often been used as an indicator of apoptosis. In the present study, U266/shRNA-Met cells possessed a higher level of cleaved caspase-3 (p17) fragments and cleaved PARP. These results reveal that the c-Met knockdown by shRNA is sufficient to trigger caspasedependent apoptosis, which could partialy be the reason for the decrease of cell viability.

The Bcl-2 family proteins have been reported to regulate apoptosis by controlling the mitochondrial membrane permeability (46). It has been found that some anti-MM agents, such as dexamethasone, thalidomide and proteasome inhibitors (PS-341), induce apoptosis in myeloma cell lines or patient cells associated with the down-regulation of Bcl-2 or/and the up-regulation of Bax (47). However, in this study, we found that although c-Met was knocked down in U266 cells and apoptosis occurred, the expression of Bcl-2 and Bax did not change. This is in agreement with the results from the study by Kitamura et al, in that the gene expression of bcl-2 or bcl-x $(\mathrm{L})$ was not affected by treatment with c-met-antisense oligonucleotides in LoVo cells (48). This suggests that apoptosis in U266 cells, induced by the knockdown of c-Met, is independent of the modulation of Bcl-2 and Bax. Future study is required in order to identify the exact mechanism.

MM had a disseminated growth pattern, with cancer cells usually spread throughout the skeleton. This dissemination is dependent on the migration of cells through endothelial barriers and on the adhesion to other cells, as well as to the matrix components. The involvement of HGF in transendothelial migration of myeloma cells has recently been documented (49). Our study also reveals that the down-regulation of c-Met expression inhibits the adhesion and invasion ability of myeloma cells in vitro, which is consistent with the results of Hov et al, in that PHA-665752, a small-molecule inhibitor of c-Met, prevents the HGF-induced migration and adhesion of myeloma cells (50). These findings suggest that c-Met could be an important target for the migration and adhesion of $\mathrm{MM}$ cells.

The importance of myeloma cell adhesion for survival and resistance to chemotherapeutic drugs has been documented in several studies $(51,52)$. Drug resistance is an important cause of treatment failure and mortality in MM patients. Lou et al reported that the inhibition of the c-Met receptor tyrosine kinase signaling enhances the chemosensitivity of glioma cell lines to CDDP (53). A recent study has also indicated that c-Met antisense oligodeoxynucleotides increases the sensitivity of human glioma cells to paclitaxel (54). In our study, the down-regulation of c-Met expression increased the chemosensitivity to doxorubicin in the human MM cell line, U266, suggesting that c-Met is an adjuvant chemotherapeutic target for MM.

We considered that more MM cell lines should be included in this study besides U266, to confirm the availability of suppression of proliferation and invasion mediated by the knockdown of c-Met in MM cells. Furthermore, animal experiments should also be performed to further confirm the inhibitory efects of proliferation and metastasis mediated by c-Met knockdown on MM in vivo. Therefore, the anti-cancer effect induced by c-Met knockdown requires further investigation. In conclusion, our findings indicate that the c-Met expression is inhibited by c-Met shRNA and that the shRNAmediated silencing of c-Met not only results in the inhibition of cell proliferation, adherence and invasive potential, but also increases the chemosensitivity to doxorubicin in U266 cells, independent of the $\mathrm{Bcl}-2$ pathway. Our results provide further evidence that c-Met is an important target for MM treatment and that the c-Met shRNA could serve as an effective tool.

\section{Acknowledgements}

This study was supported by the National Natural Science Foundation of China (grant no. 30871111).

\section{References}

1. Kyle RA and Rajkumar SV: Multiple myeloma. N Engl J Med 351: 1860-1873, 2004

2. Richardson PG: A review of the proteasome inhibitor bortezomib in multiple myeloma. Expert Opin Pharmacother 5: 1321-1331, 2004.

3. Richardson PG, Mitsiades CS, Hideshima T and Anderson KC: Novel biological therapies for the treatment of multiple myeloma. Best Pract Res Clin Haematol 18: 619-634, 2005.

4. Harousseau JL: Stem cell transplantation in multiple myeloma. Curr Opin Oncol 17: 93-98, 2005.

5. Ghobrial IM, Leleu X, Hatjiharissi E, et al: Emerging drugs in multiple myeloma. Expert Opin Emerg Drugs 12: 155-163, 2007.

6. Pagnucco G, Cardinale $G$ and Gervasi F: Targeting multiple myeloma cells and their bone marrow microenvironment. Ann N Y Acad Sci 1028: 390-399, 2004.

7. Damiano JS, Cress AE, Hazlehurst LA, et al: Cell adhesion mediated drug resistance (CAM-DR): role of integrins and resistance to apoptosis in human myeloma cell lines. Blood 93: 1658-1667, 1999.

8. Hideshima T, Chauhan D, Hayashi T, et al: The biological sequelae of stromal cell derived factor- 1 alpha in multiple myeloma. Mol Cancer Ther 1: 539-544, 2002.

9. Damiano JS and Dalton WS: Integrin-mediated drug resistance in multiple myeloma. Leuk Lymphoma 38: 71-81, 2000.

10. Hideshima T, Nakamura N, Chauhan D and Anderson KC: Biologic sequelae of interleukin-6 induced PI3-K/Akt signaling in multiple myeloma. Oncogene 20: 5991-6000, 2001.

11. Hideshima T, Podar K, Chauhan D and Anderson KC: Cytokines and signal transduction. Best Pract Res Clin Haematol 18: 509-524, 2005.

12. Gupta D, Treon SP, Shima Y, et al: Adherence of multiple myeloma cells to bone marrow stromal cells upregulates vascular endothelial growth factor secretion: therapeutic applications. Leukemia 15: 1950-1961, 2001.

13. Akiyama M, Hideshima T, Hayashi T, et al: Cytokines modulate telomerase activity in a human multiple myeloma cell line. Cancer Res 62: 3876-3882, 2002.

14. Roccisana J, Reddy V, Vasavada RC, et al: Targeted inactivation of hepatocyte growth facto receptor c-Met in $\beta$-cells leads to defective insulin secretion and GLUT-2 down regulation with out alter ation of $\beta$-cell mass. Diabetes 54: 2090-2102, 2005.

15. Giordano S, Ponzetto C, DiRenzo MF, et al: Tyrosine kinase receptor in distinguish able from the c-Met protein. Nature 339: 155-156, 1989.

16. Camp RL, Rimn EB and Rimm DL: Met expression is associated with poor outcome in patients with axillary lymph node negative breast carcinoma. Cancer 86: 2259-2265, 1999.

17. Cheng HL, Liu HS, Lin YJ, et al: Co-expression of RON and MET is a prognostic indicator for patients with transitional cell carcinoma of the bladder. Br J Cancer 92: 1906-1914, 2005. 
18. Borset M, Lien E, Espevik T, et al: Concomitant expression of hepatocyte growth factors catter factor and the receptor c-MET in human myeloma cell lines. J Biol Chem 271: 24655-24661, 1996.

19. Borset M, Hjorth-Hansen H, Seidel C, et al: Hepatocyte growth factor and its receptor c-Met in multiple myeloma. Blood 88 3998-4004, 1996.

20. Bernstein E, Caudy AA, Hammond SM and Hannon GJ: Role for a bidentate ribonuclease in the initiation step of RNA interference. Nature 409: 363-366, 2001.

21. Xie Z, JI C and Chen J: Construction and identification of recombinant plasmids containing short hairpin RNA targeting c-Met gene. Chinese Archives of Otolaryngology-Head and Neck Surgery 16: 251-254, 2009.

22. Wang S, Liu H, Ren L, et al: Inhibiting colorectal carcinoma growth and metastasis by blocking the expression of VEGF using RNA interference. Neoplasia 10: 399-407, 2008.

23. Uemura K, Takao S and Aikou T: In vitro determination of basement membrane invasion predicts liver metastases in human gastro intestinalcarcinoma. Cancer Res 58: 3727-3731, 1998.

24. Jin M, He S, Worpel V, et al: Promotion of adhesion and migration of RPE cells to provisional extracellular matrices by TNF- $\alpha$. Invest Ophthalmol Vis Sci 41: 4324-4332, 2000.

25. Wang SM, Zhu J, Pan LF and Liu YK: Inhibitory effect of dimeric $\beta$ peptide on the recurrence and metastasis of hepatocellular carcinoma in vitro and in mice. World J Gastroenterol 14 3054-3058, 2008.

26. Ramos-Nino ME, Blumen SR, Sabo-Attwood T, et al: HGF mediates cell proliferation of human mesothelioma cells through a PI3K/MEK5/Fra-1pathway. Am J Respir Cell Mol Biol 38: 209-217, 2008

27. Chu SH, Yuan XH, Li ZQ, et al: C-Met antisense oligodeoxynucleotide inhibits growth of glioma cells. Surg Neurol 65 533-538, 2006

28. Jiang $\mathrm{Y}, \mathrm{Xu} \mathrm{W}, \mathrm{Lu} \mathrm{J}$, et al: Invasiveness of hepatocellular carcinoma celllines: contribution of hepatocyte growth factor c-met, and transcription factor ets-1. Biochem Biophys Res Commun 286: 1123-1130, 2001.

29. Chu SH, Feng DF, Zhang H, et al: c-Met-targeted RNA interference inhibits growth and metastasis of glioma U251 cells in vitro. J Neurooncol 93: 183-189, 2009.

30. Seidel C, Borset M, Turesson I, et al: Elevated serum concentrations of hepatocyte growth factor in patients with multiple myeloma: The Nordic Myeloma Study Group. Blood 91: 806-812, 1998.

31. Di Raimondo F, Azzaro MP, Palumbo G, et al: Angiogenic factors in multiple myeloma: higher levels in bone marrow than in peripheral blood. Haematologica 85: 800-805, 2000.

32. Sezer O, Jakob C, Eucker J, et al: Serum levels of the angiogenic cytokines basic fibroblast growth factor (bFGF), vascular endothelial growth factor (VEGF) and hepatocyte growth factor (HGF) in multiple myeloma. Eur J Haematol 66: 83-88, 2001.

33. Seidel C, Lenhoff S, Brabrand S, et al: Hepatocyte growth factor in myeloma patients treated with high-dose chemotherapy. $\mathrm{Br} J$ Haematol 119: 672-676, 2002.

34. Borset M, Lien E, Espevik T, et al: Concomitant expression of hepatocyte growth factors catter factor and the receptor c-MET in human myeloma cell lines. J Biol Chem 271: 24655-24661, 1996.

35. Tjin EP, Groen RW, Vogelzang I, et al: Function alanalysis of HGF/MET signaling and aberrant HGF-activator expression in diffuse large B-cell lymphoma. Blood 107: 760-768, 2006.

36. Chu SH, Feng DF, Zhang H, et al: c-Met-targeted RNA interference inhibits growth and metastasis of glioma U251 cells in vitro. J Neurooncol 93: 183-189, 2009.
37. Ji CY, Xie ZN, Chen JC, et al: RNA interference targeting c-Met inhibits proliferation of human laryngeal carcinoma Hep-2 cell line in vitro and in its xenografts in nude mice. Zhonghua $\mathrm{Er} \mathrm{Bi}$ Yan Hou Tou Jing Wai Ke Za Zhi 45: 61-67, 2010.

38. Aluigi M, Fogli M, Curti A, et al: Nucleofection is an efficient nonviral transfection technique for human bone marrow-derived mesenchymal stem cells. Stem Cells 24: 454-461, 2006.

39. Hov H, Tian E, Holien T, et al: c-Met signaling promotes IL-6 induced myeloma cell proliferation. Eur J Haematol 82: 277-287, 2009.

40. Du W, Hattori Y, Yamada T, et al: NK4, anantagonist of hepatocyte growth factor (HGF), inhibits growth of multiple myeloma cells: molecular targeting of angiogenic growth factor. Blood 109: 3042-3049, 2007.

41. Stellrecht CM, Phillip CJ, Cervantes-Gomez F and Gandhi V: Multiple myeloma cell killing by depletion of the MET receptor tyrosine kinase. Cancer Res 67: 9913-9920, 2007.

42. Munshi N, Jeay S, Li Y, et al: ARQ 197, a novel and selective inhibitor of the human c-Met receptor tyrosine kinase with antitumor activity. Mol Cancer Ther 9: 1544-1553, 2010.

43. Uddin S, Hussain AR, Ahmed M, et al: Inhibition of c-MET is a potential therapeutic strategy for treatment of diffuse large B-cell lymphoma. Lab Invest 90: 1346-1356, 2010.

44. Derksen PW, de Gorter DJ, Meijer HP, et al: The hepatocyte growth factor/Met pathway controls proliferation and apoptosis in multiple myeloma. Leukemia 17: 764-774, 2003.

45. Kaufman SH: Induction of endonucleolytic DNA cleavage in human acute myelogenous leukemia cell by etoposide, camptothecin and other cytotoxic anticancer drugs: a cautionary note. Cancer Res 49: 5870-5878, 1989.

46. Oltvai ZN, Milliman CL and Korsmeyer K: Bcl-2 heterodimerizes in vivo with a conserved homolog, Bax, that accelerates programmed cell death. Cell 74: 609-619, 1993.

47. Mitsiades N, Mitsiades C, Poulaki V, et al: Biologic sequelae of nuclear factor-B blockade in multiple myeloma: therapeutic applications. Blood 99: 4079-4086, 2002.

48. Kitamura S, Kondo S, Shinomura Y, et al: Met/HGF receptor modulates bcl-w expression and inhibits apoptosis in human colorectal cancers. Br J Cancer 83: 668-673, 2000.

49. Vande BI, Asosingh K, Allegaert V, et al: Bone marrow endothelial cells increase the invasiveness of human multiple myeloma cells through upregulation of MMP-9: evidence for a role of hepatocyte growth factor. Leukemia 18: 976-982, 2004.

50. Hov H, Holt RU, Ro TB, et al: A selective c-Met inhibitor blocks an autocrine hepatocyte growth factor loop in ANBL-6 cells and prevents migration and adhesion of myeloma cells. Clin Cancer Res 10: 6686-6694, 2004.

51. Hazlehurst LA, Damiano JS, Buyuksal I, et al: Adhesion to fibronectin via $\beta 1$ integrins regulates $\mathrm{p} 27 \mathrm{kip} 1$ levels and contributes to cell adhesion mediated drug resistance (CAM-DR). Oncogene 19: 4319-4327, 2000.

52. Uchiyama H, Barut BA, Mohrbacher AF, et al: Adhesion of human myeloma-derived cell lines to bone marrow stromal cells stimulates interleukin-6 secretion. Blood 82: 3712-3720, 1993.

53. Lou X, Zhou Q, Yin Y, Zhou C and Shen Y: Inhibition of the met receptor tyrosine kinase signaling enhances the chemosensitivity of glioma cell lines to CDDP through activation of p38 MAPK pathway. Mol Cancer Ther 8: 1126-1136, 2009.

54. Chu SH, Ma YB, Feng DF, et al: c-Met antisense oligodeoxynucleotides increase sensitivity of human glioma cells to paclitaxel. Oncol Rep 24: 189-194, 2010. 